ISSN: 0213-2087 e-ISSN: 2444-7080

DOI: https://doi.org/10.14201/shhcont382020151174

\title{
HOMBRES ESPAÑOLES DESPLAZADOS: MASCULINIDADES Y NACIÓN EN LOS EXILIOS Y MIGRACIONES ESPAÑOLES DURANTE EL FRANQUISMO
}

\author{
Displaced Spanish Men: Masculinities and Nation \\ in Spanish Exiles and Migrations during Francoism
}

\author{
Iker GONZÁLEZ-ALLENDE \\ University of Nebraska-Lincoln
}

Recibido: 14/02/2020 Revisado: 06/06/2020 Aceptado: 19/06/2020

RESUMEN: Este artículo explora las situaciones de desventaja y los padecimientos de los hombres españoles en los exilios y emigraciones durante el franquismo y su repercusión en su masculinidad. Los hombres españoles se regían por una masculinidad cívica, basada en valores como el trabajo, la paternidad y la división clara y tradicional entre los papeles de los hombres y de las mujeres. Su salida de España y la vida en el país de acogida supusieron un desafío a su modelo de masculinidad, causando en ellos sensaciones de crisis, impotencia e inestabilidad. A pesar de posibles consecuencias positivas que pudieron reafirmar su masculinidad, como una mejora de su situación económica y una mayor libertad, los hombres desplazados tendieron a sentirse derrotados al abandonar España, padecieron dificultades para adaptarse al nuevo país y sufrieron discriminación y xenofobia. Frente a estas experiencias emasculantes, recurrieron a diversas estrategias para remasculinizar su identidad, tales como su dignidad moral y su compromiso político.

Palabras clave: Masculinidad; hombres españoles; exilio; emigración; franquismo; España

ABSTRACT: This article explores the disadvantageous situations and sufferings of Spanish men in exiles and migrations during Francoism and the subsequent impacts on their masculinity. Spanish men followed a civic masculinity, based on values such as work, fatherhood and a clear and traditional division of gender roles. Leaving Spain and living in 
the host country challenged their model of masculinity, causing in them feelings of crisis, impotence and instability. Despite possible positive consequences that could reaffirm their masculinity, such as an improvement of their economic situation and a greater freedom, displaced Spanish men used to feel defeated when leaving Spain, suffered difficulties in adapting to the new country and faced discrimination and xenophobia. To counteract these emasculating experiences, they resorted to multiple strategies to remasculinize their identities, such as their moral dignity and political commitment.

Key words: Masculinity; Spanish men; exile; migration; Francoism; Spain.

En uno de sus ensayos escrito en 1977, el filósofo Adolfo Sánchez Vázquez, quien vivió exiliado en México desde 1939, subraya la condición trágica del destierro: «El exiliado vive siempre escindido: de los suyos, de su tierra, de su pasado. [...] es no sólo la pérdida de la tierra propia, sino con ello la pérdida de la tierra como raíz o centro» ${ }^{1}$. Una semejante visión del dolor que se padece estando lejos de la patria la ofrece Patricio Chamizo, quien emigró a Alemania en los años 60 y reflejó la nostalgia del emigrante en su obra En un lugar de Alemania... (1967), donde uno de los personajes se siente morir al escuchar una grabación de su familia que sigue en España: "se llevó una mano al cuello con síntomas inequívocos de asfixia. [...] rompió a llorar de bruces sobre la mesa. [...] ;Eu morro, eu morro! ’ $^{2}$. A pesar de la distancia cronológica entre el exilio republicano de la Guerra Civil y la emigración de la década de 1960 y las diferencias significativas de clase social, razones para abandonar España y situaciones de los países de acogida de los exiliados y emigrantes, estos dos testimonios revelan cómo el desplazamiento territorial forzado puede impactar de manera indeleble en la identidad y la autoestima masculina de los hombres ${ }^{3}$.

Aunque las sensaciones de desarraigo, así como las nuevas oportunidades en el país de destino afectan tanto a los hombres como a las mujeres que abandonan su país, ambos grupos suelen enfrentarse al exilio y la emigración de forma diferente. Inversamente, la identidad de género y la sexualidad de la persona también pueden cambiar o modificarse como consecuencia de la emigración y el exilio, ya que cuando un individuo vive en una cultura nueva, es común que se halle ante una concepción de género diferente que le lleve a ser más consciente del modelo de género en el que se ha formado. Martin Manalansan indica al respecto que emigrar puede transformar

1. SÁnchez VÁzquez, Adolfo: Del exilio en México: Recuerdos y reflexiones. México D.F.: Grijalbo, 1997 , p. 36.

2. Chamizo, Patricio: En un lugar de Alemania... Madrid: Editorial ZYX, 1967, p. 84.

3. Parecida sensación experimentan los emigrantes españoles contemporáneos. En 2014, Josep, un joven bibliotecario español emigrante en Edimburgo, explica en el documental En tierra extraña que tras varios años viviendo fuera del país de origen, "tu identidad, aunque te consideras de tu tierra, ha cambiado y te has perdido muchas cosas que han pasado en esa tierra durante ese tiempo» (57.48). 
y perturbar las nociones estáticas de género y sexualidad ${ }^{4}$. Por este motivo, Eithne Luibhéid subraya que resulta imprescindible prestar atención a las variables de género y sexualidad para poder entender y analizar cualquier tipo de migración’.

Sin embargo, hasta la década de 1990, los estudios migratorios no han solido tener en cuenta el género en sus análisis, y las mujeres solían quedar reducidas a meras acompañantes de los hombres —esposas, madres, hijas, hermanas—, sin otorgárseles ninguna agencia en el movimiento migratorio. Desde entonces, han surgido numerosos trabajos sobre las experiencias exílicas y migratorias de las mujeres. Como diversas investigadoras señalan, los desplazamientos territoriales tienden a mejorar las condiciones de vida de las mujeres, permitiéndoles romper con los papeles tradicionales de género y obtener una mayor libertad ${ }^{6}$. Ahora bien, como indica Pilar Domínguez Prats en referencia al exilio republicano, la incorporación de las mujeres al trabajo remunerado se suele considerar como algo provisional hasta que la economía familiar mejore y no impide que se siga identificando a las mujeres con el ámbito doméstico y las tareas del hogar ${ }^{7}$. Además, Oliva Espín advierte que pueden incrementarse los controles patriarcales de la comunidad emigrante sobre los comportamientos femeninos con el objetivo de preservar el ideal de pureza de la mujer nacional y afianzar su superioridad moral por encima de la de la sociedad de acogida ${ }^{8}$.

\section{LaS MASCUlinidades MÓVILES DE LOS HOMBRES DESPlaZADOS}

En relación con los hombres exiliados y emigrantes, utilizo el término «hombres desplazados» para referirme a ellos con el objetivo de englobar en un análisis conjunto el estudio de sus experiencias en el país de acogida, puesto que ambos grupos padecen similares vivencias que fisuran su sentido de la masculinidad. El adjetivo "desplazado» alude, por un lado, a la separación física de su nación de origen y su traslado a una

4. Manalansan, Martin F.: "Queer Intersections: Sexuality and Gender in Migration Studies", International Migration Review, 40.1, 2006, p. 243.

5. LuibHÉID, Eithne: "Queer/Migration: An Unruly Body of Scholarship», GLQ: A Journal of Lesbian and Gay Studies, 14(2-3), 2008, p. 171.

6. Pedraza, Silvia: "Women and Migration: The Social Consequences of Gender", Annual Review of Sociology, 17, 1991, p. 321.

7. Domínguez Prats, Pilar: «Mujeres españolas exiliadas en México (1939-1950)». En: Médulas que han gloriosamente ardido: El papel de la mujer en el exilio español. México: Ateneo Español de México, 1994, p. 85.

8. Espín, Oliva M.: Women Crossing Boundaries: A Psychology of Immigration and Transformations of Sexuality. New York: Routledge, 1999, pp. 128-9. Debido a estos resultados contradictorios en las vidas de las mujeres emigrantes, Patricia Pessar indica que la emigración simultáneamente refuerza y debilita el patriarcado en sus múltiples formas. Pessar, Patricia R.: "Engendering Migration Studies: The Case of New Immigrants in the United States». En: Hondagneu-Sotelo, Pierrette (ed.): Gender and U.S. Migration: Contemporary Trends. Berkeley: University of California Press, 2003, p. 20. 
nueva y, por otro, al significado de inadaptado al ambiente o las circunstancias, una realidad común en los testimonios de estos hombres.

Tradicionalmente los investigadores han tratado a los hombres desplazados como los principales sujetos de los estudios migratorios, enfocándose en sus retos económicos y su adaptación cultural al nuevo país. Ahora bien, las experiencias de estos varones se han solido universalizar, mientras que su género y sexualidad se han obviado hasta época reciente. Para remediar esta exclusión, desde comienzos del siglo XXI, algunos investigadores como Raymond Hibbins, Bob Pease y Ernesto Vásquez del Águila han empezado a prestar atención a la masculinidad de los hombres emigrantes. Estos estudios han revelado la necesidad de analizar a los varones desplazados como hombres, esto es, como individuos con un género y una sexualidad, y explorar cómo su masculinidad e identidad son afectadas por la separación de su patria. Las investigaciones sobre los hombres desplazados suelen enfatizar su pérdida de estatus social en el nuevo país y las dificultades que suponen para su autoestima masculina vivir en una sociedad con unas normas de género diferentes a las de su nación de origen. A menudo se termina ofreciendo una imagen negativa de ellos al relacionarlos con la criminalidad, el sexismo, la violencia doméstica y los matrimonios forzados9 . Frente a esta visión homogeneizadora, Katharine Charsley y Helena Wray abogan por la necesidad de investigar sus vulnerabilidades y sus realidades afectivas porque no todos los hombres se benefician de la misma manera del dividendo patriarcal ${ }^{10}$.

En este artículo me propongo, precisamente, explorar las situaciones de desventaja y los padecimientos de los hombres españoles en los exilios y emigraciones durante el franquismo para investigar cómo repercuten en su masculinidad. Para ello planteo la existencia de la masculinidad nacional hegemónica, consistente en el ideal de masculinidad promovido por las ideologías nacionales en una época concreta, que en el caso de los españoles exiliados y emigrantes estribaba en la masculinidad cívica, basada en valores como el trabajo, la paternidad y la división clara y tradicional entre los papeles de los hombres y de las mujeres. Por medio del análisis de narrativas de vida del exilio en México y la emigración en Alemania —esto es, obras de diversa índole (auto)biográfica donde los autores que padecieron el exilio o la emigración reflexionan sobre las experiencias vitales lejos de España-, se revela cómo sus circunstancias personales y ambientales en el país de acogida causan en su masculinidad sensaciones

9. TrąBKA, Agnieszka y Wojnicka, Katarzyna: "Self-Positioning as a Man in Transnational Contexts: Constructing and Managing Hybrid Masculinity", Norma: International Journal for Masculinity Studies, 12(2), 2017 , p. 145 .

10. Charsley, Katharine y Wray, Helena: «Introduction: The Invisible (Migrant) Man», Men and Masculinities, 18(4), 2015, p. 411. Estas autoras reconocen que puede resultar polémico estudiar a los hombres migrantes cuando existen numerosos escenarios de vulnerabilidad de las mujeres migrantes como víctimas de tráfico sexual y de matrimonios de conveniencia (p. 415). Sin embargo, esto no debe impedir que se preste atención también a los hombres migrantes y a su situación de desprotección. 
de crisis, impotencia e inestabilidad. A pesar de posibles consecuencias positivas que pueden reafirmar su masculinidad, como una mejora de su situación económica y una mayor sensación de libertad, los hombres desplazados tienden a sentirse derrotados al abandonar España, padecen dificultades para adaptarse al nuevo país y en él sufren aislamiento, discriminación y xenofobia. Frente a estas experiencias emasculantes, pueden recurrir a estrategias de compensación para remasculinizar su identidad, tales como su dignidad moral y sacrificio, el compromiso político y el asociacionismo, y actitudes hipermasculinas como la violencia.

La comparación entre los hombres exiliados y emigrantes revela que la tradicional división entre exilio y emigración no siempre resulta útil. En los estudios clásicos se ha definido el exilio como una marcha forzada del país por motivos políticos-ideológicos y la emigración como un abandono más o menos voluntario del lugar de origen por razones económicas ${ }^{11}$. Sin embargo, recientemente se han demostrado las semejanzas existentes entre ambos fenómenos. Es cierto que el exiliado puede experimentar una mayor sensación de fracaso que el emigrante porque es un derrotado político, pero el emigrante también puede considerar que su salida del país constituye una derrota personal. Por otro lado, la división tradicional entre motivos políticos y económicos para abandonar el país no siempre resulta clara, ya que los males económicos y sociales que provocan la emigración laboral son en numerosas ocasiones consecuencia de sistemas políticos que no han gestionado el país de manera adecuada ${ }^{12}$. La voluntariedad como rasgo definitorio del emigrante también es debatible, ya que éste puede sentirse obligado a dejar su país porque no encuentra ninguna solución factible para ganarse la vida. Debido a estas similitudes, el análisis conjunto de hombres exiliados y emigrantes ofrece una perspectiva más reveladora de cómo la masculinidad y la nación conforman un binomio interdependiente.

Aunque la mayoría de los hombres desplazados durante el franquismo experimenta una caída de su autoestima masculina, pueden reaccionar en un espectro de posibilidades, desde la ostentación de una virilidad extrema, hasta el padecimiento de depresiones e incluso la adopción de una identidad de género más fluida, cambiando la estricta separación de los papeles de género que solían practicar en España. Esta diversidad de comportamientos, empero, no necesariamente implica una modificación en su concepción de la masculinidad, es decir, su visión de lo que es o debería ser un hombre ${ }^{13}$. De esta manera, es común que cambien su conducta hacia un modelo

11. Ascunce, José Ángel: «Exilio y emigración. De la experiencia del emigrante al compromiso del exiliado: Amado Alonso y Ramón de Belausteguigoitia», en GonzÁlez de GARAY, María Teresa y DíAz-Cuesta, José (eds.): El exilio literario de 1939, 70 años después. Logroño: Universidad de La Rioja, 2013, p. 165.

12. ANDRÉS-SUÁREZ, Irene: “Introducción», en: La inmigración en la literatura española contemporánea. Madrid: Verbum, 2002, p. 18.

13. GonzÁlez-Allende, Iker: Hombres en movimiento: Masculinidades españolas en los exilios y emigraciones, 1939-1999. West Lafayette, IN: Purdue University Pess, 2018, p. 243. 
de género más igualitario, por ejemplo, realizando tareas domésticas o aceptando la incorporación de sus esposas al mercado laboral, pero lo hagan obligados por las circunstancias, no porque realmente crean en la igualdad entre hombres y mujeres ${ }^{14}$.

A pesar de estos rasgos generales, resulta necesario enfatizar que cada emigrante o exiliado se enfrenta a su proceso de desplazamiento territorial de manera única y diferente, y su masculinidad también se verá afectada de forma distinta, en un continuum desde la vivencia de una gran crisis hasta un mínimo cambio o incluso sensación de mayor felicidad. Además, el comportamiento y la concepción de la masculinidad de los hombres desplazados pueden evolucionar y modificarse a medida que pasan años en el país de acogida. Por ejemplo, un hombre exiliado puede comenzar su destierro con una actitud positiva - debido a las novedades o la paz existentes en la tierra de asilo, o debido a su esperanza en el retorno a España- y después su estado de ánimo puede transformarse y sentirse desilusionado e impotente, o viceversa.

En la vivencia de la masculinidad de los hombres desplazados influyen múltiples factores personales, por lo que prestar atención a la interseccionalidad resulta imprescindible en su estudio. Como indican Charsley y Wray, no todos los hombres desplazados son igualmente vulnerables ${ }^{15}$. Así, su masculinidad se modificará dependiendo de una miríada de variables que repercuten en la vivencia general de la emigración y el exilio, tales como la edad, la clase social, el estado civil, la orientación sexual, las personas con las que viaja y dependen de él, el trabajo que obtiene en el nuevo país, la comunidad y el ambiente en los que vive, el contacto con sus compatriotas y su relación con ellos, la comunicación con los familiares y amigos que permanecen en España, el tiempo que lleva fuera del país y las posibilidades de regresar a España. De todos estos factores, la edad en la que uno emigra o se exilia es especialmente significativa debido a su conexión con los procesos cognitivos y el desarrollo psicológico. Se suele señalar al respecto que las personas que abandonan su país a una edad temprana tienden a adaptarse más fácil y rápidamente.

Como las circunstancias que experimentan en el exilio o la emigración afectan a su percepción como hombres y pueden transformar la manera en la que ejecutan performativamente su masculinidad, es posible hablar de "masculinidades móviles» para referirse a la virilidad de los hombres desplazados. Al poseer un modelo de masculinidad que difiere ligera o significativamente del presente en la sociedad de acogida, los exiliados y emigrantes tienden a percatarse de la existencia de múltiples formas de ser hombre. R. W. Connell indica que en una misma sociedad conviven diversas masculinidades, las cuales se hallan en una relación jerárquica de poder ${ }^{16}$.

14. Pease, Bob: "Immigrant Men and Domestic Life: Renegotiating the Patriarchal Bargain?». En: Donaldson, Mike et al. (eds.): Migrant Men: Critical Studies of Masculinities and the Migration Experience. New York: Routledge, 2009, p. 86.

15. Charsley, Katharine y Wray, Helena: op. cit., p. 409.

16. Connell, R. W.: Masculinities. Berkeley: University of California Press, 2005, p. 76. 
Debido a la situación de desventaja de la mayoría de los hombres desplazados, se puede argumentar que encarnan una "masculinidad marginalizada». Connell utiliza este término para describir la virilidad de los hombres que por su clase social trabajadora o su raza no blanca permanecen en los márgenes del poder masculino en la sociedad ${ }^{17}$. Aunque Connell no menciona la migración o la condición de ser extranjero como circunstancias individuales que provocan la masculinidad marginalizada, no cabe duda de que perjudican a los hombres en la escala jerárquica de masculinidad de manera significativa. Al ser expulsados del país o verse impelidos a abandonarlo por motivos políticos y/o económicos, su masculinidad se convierte en marginalizada porque pasan a ser excedentes de España, no son tenidos en cuenta en ella y pierden su estatus como ciudadanos activos de la nación. A ello hay que sumarle la falta de derechos políticos y sociales que padecen en los países de acogida, donde generalmente también sufren discriminación y xenofobia. De esta manera, los hombres desplazados habitan en un limbo nacional, en los márgenes de las naciones de origen y de acogida.

Por su posición vulnerable, los hombres exiliados y emigrantes se hallan lejos de personificar la "masculinidad hegemónica", que consiste en el tipo de masculinidad más valorada culturalmente en la sociedad y que solo una minoría de hombres es capaz de poseer ${ }^{18}$. Ahora bien, esto no significa que estos hombres no se sigan beneficiando de los privilegios derivados del sistema patriarcal. Por este motivo, a menudo presentan la denominada "masculinidad cómplice», la cual describe a aquellos hombres que, aunque no encarnan la masculinidad hegemónica, la apoyan y se benefician del patriarcado ${ }^{19}$. Esto se aprecia cuando los hombres exiliados y emigrantes admiran de manera nostálgica modelos tradicionales de la masculinidad española como el don Juan o el torero, o demuestran que, a pesar de su falta de poder, siguen manteniendo una visión tradicional del papel del hombre en la sociedad.

La existencia de una jerarquía de masculinidades provoca que la vivencia del exilio y la emigración tenga una especial repercusión en la identidad y sensación de valía de los hombres, a diferencia de lo que sucede en el caso de las mujeres. No cabe

17. Ibid., p. 80 .

18. Connell, R. W. y Messerschmidt, James: «Hegemonic Masculinity: Rethinking the Concept», Gender and Society, 19(6), 2005, p. 832. Aunque el término "masculinidad hegemónica» difundido por Connell ha tenido una muy amplia aceptación y se ha utilizado y sigue utilizándose en incontables ocasiones —a menudo de forma errónea porque se usa como sinónimo de masculinidad tóxica一, ha recibido también algunas detracciones. Connell y Messerschmidt recogieron algunas de estas críticas: es un término que puede esencializar y producir una tipología estática, resulta ambiguo porque hay hombres que poseen poder social pero no representan una masculinidad ideal y puede adquirir una connotación negativa al identificarse con una masculinidad violenta (pp. 836-41). A pesar de ello, ambos autores defienden que de la definición original del término se debe todavía mantener la existencia de una pluralidad de masculinidades, la jerarquía de éstas y el hecho de que es la masculinidad socialmente dominante (p. 846).

19. Connell, R. W.: op. cit., p. 79. 
duda de que las experiencias deshumanizantes y alienadoras a las que se enfrentan los hombres exiliados y emigrantes, como la separación familiar y la discriminación, también las padecen las mujeres. De hecho, algunos críticos señalan que las mujeres desplazadas sufren más que los hombres por su mayor vulnerabilidad ${ }^{20}$. Sin embargo, estas dificultades en el país de acogida no suponen para la mujer un cuestionamiento de su feminidad — debido a su asociación tradicional con la debilidad y la expresión de sentimientos-, mientras que para el hombre sí implican fisuras y dudas sobre su masculinidad, ya que entran en conflicto con la construcción cultural masculina que enfatiza el raciocinio y el control de las emociones. De esta manera, el exilio y la emigración desestabilizan el poder masculino sobre el que se erige el ideal de masculinidad. Michael Kimmel identifica precisamente la masculinidad hegemónica con el poder: "The hegemonic definition of manhood is a man in power, a man with power, and a man of power ${ }^{21}$. La autoestima de los hombres desplazados también suele verse mermada porque su vida en el nuevo país carece generalmente de reconocimiento social. Es importante resaltar en este sentido que la masculinidad no se construye como una condición innata de los hombres, sino como algo que éstos tienen que conseguir permanentemente por medio de sus actos para demostrar a los otros hombres que son lo suficientemente masculinos. Son ellos los que confieren la masculinidad ${ }^{22}$.

\section{LA MASCULINIDAD NACIONAL HEGEMÓNICA Y LA MASCULINIDAD CÍVICA}

Además de existir en cada sociedad una masculinidad hegemónica, los proyectos nacionales asimismo elaboran un ideal de masculinidad para sus ciudadanos, el cual podría denominarse «masculinidad nacional hegemónica». En una misma nación conviven compitiendo distintos modelos de masculinidad nacional dependiendo de cada ideología, pero aquel que domina en el imaginario nacional de los ciudadanos es el hegemónico. Al mismo tiempo que se construye un ideario nacional, se prescribe un modelo normativo de género para los hombres y las mujeres de esa nación. Así lo indica George Mosse en relación con la aparición de los nacionalismos en el siglo XIX: "Nationalism and respectability assigned everyone his place in life, man and

20. Edurne Elgorriaga et al. comentan que la falta de recursos, el conflicto de valores, la violencia de género y el trabajo doméstico provocan que las mujeres migrantes padezcan de una peor salud mental que los hombres. Elgorriaga, Edurne et al:: "Spanish Migrants to European Union Countries: Predictors of Psychological Adjustment,, Revista de Psicología Social, 31(2), 2016, p. 333.

21. Kimmel, Michael: "Masculinity as Homophobia: Fear, Shame, and Silence in the Construction of Gender Identity", en Brod, Harry y Kaufman, Michael (eds.): Theorizing Masculinities. London: Sage, 1994, p. 125.

22. Por este motivo, para Kimmel la masculinidad consiste en un acto homosocial: «Masculinity is a homosocial enactment. We test ourselves, perform heroic feats, take enormous risks, all because we want other men to grant us our manhood». Kimmel, Michael: op. cit., p. 129. 
woman, normal and abnormal, native and foreginer ${ }^{23}$. La masculinidad nacional hegemónica suele constituirse con una visión tradicional de las funciones del hombre en la nación. Investigadoras como Joane Nagel han señalado al respecto que las ideologías nacionales suelen ser patriarcales y conservadoras en lo referente al género sexual ${ }^{24}$. Los nacionalismos institucionalizan y normalizan la heterosexualidad, excluyendo las identidades no heterosexuales y naturalizando la familia patriarcal ${ }^{25}$. Las ideologías nacionales diferencian claramente los papeles de los hombres y de las mujeres para dar la impresión de que su construcción de género es natural, en vez de creada cultural y socialmente. Además, suelen considerar que una división estricta entre hombres y mujeres es necesaria para crear una nación fuerte y vigorosa ${ }^{26}$.

En este binarismo de género promovido por los nacionalismos, los hombres se representan como los miembros activos de la patria: su vigor y fortaleza simbolizan la vitalidad de la nación y las esperanzas de su futuro próspero ${ }^{27}$. La masculinidad nacional hegemónica implica que el hombre posea cualidades positivas tanto física como moralmente: su fuerza y atractivo físico van acompañados de la caballerosidad y la virtud $^{28}$. Otros valores que suelen considerarse propios del modelo ideal del hombre de la nación son la valentía, el altruismo, el patriotismo y la defensa de la nación, generalmente representada en la protección de las mujeres y los niños.

Estas características de la masculinidad nacional eran las prevalecientes en España durante la Segunda República. Como ha descrito Nerea Aresti, en la década de 1930, a partir de las premisas de Gregorio Marañón, se promueve en España un nuevo ideal masculino, alejado del arquetipo del don Juan y basado en el autocontrol, la moderación sexual, la responsabilidad familiar y el trabajo ${ }^{29}$. Miren Llona también señala el

23. Mosse, George L.: Nationalism and Sexuality: Respectability and Abnormal Sexuality in Modern Europe. New York: H. Fertig, 1985, p. 16. Ahora bien, los nacionalismos asimismo pueden incorporar a algunos sujetos homosexuales en sus proyectos nacionales - lo que Jasbir Puar denomina "homonacionalismo»-, especialmente para construir la imagen de una nación excepcional en oposición a individuos de raza no blanca y de religión musulmana: «some homosexual subjects are complicit with heterosexual nationalist formations rather than inherently or automatically excluded from or opposed to them». PUAR, Jasbir K.: Terrorist Assemblages: Homonationalism in Queer Times. Durham: Duke University Press, 2007 , p. 4.

24. NAGel, Joane: "Masculinity and Nationalism: Gender and Sexuality in the Making of Nations", Ethnic and Racial Studies, 21(2), 1998, p. 254.

25. Peterson, V. Spike: «Sexing Political Identities / Nationalism as Heterosexism». En: RANCHOD-NiLSSON, Sita y Tétreault, Mary Ann (eds.): Women, States and Nationalisms: At Home in the Nation? London: Routledge, 2000, p. 59.

26. BRAudy, Leo: From Chivalry to Terrorism: War and the Changing Nature of Masculinity. New York: Alfred A. Knopf, 2003, p. 332.

27. Mosse, George L.: The Image of Man: The Creation of Modern Masculinity. New York: Oxford University Press, 1996, p. 3.

28. Ibid., p. 23.

29. ARESTI, Nerea: Masculinidades en tela de juicio: Hombres y género en el primer tercio del siglo XX. Madrid: Cátedra, 2010, p. 265. 
afianzamiento de este modelo de respetabilidad masculina opuesto al de conquistador de mujeres, aunque subraya que este cambio de masculinidad en el discurso público no siempre se llevaba a cabo posteriormente en la práctica ${ }^{30}$. El socialismo español asimismo adoptó este ideal de masculinidad respetable para contrarrestar la visión estigmatizada de los hombres trabajadores, proponiendo a través de Pablo Iglesias valores como la rectitud de carácter, la inteligencia, la formalidad y la abnegación ${ }^{31}$. Resulta destacable la semejante concepción tradicional de masculinidad y de género - con una clara división de funciones entre hombres y mujeres - que las ideologías políticas conservadoras y progresistas compartían en los años 30.

Esta coincidencia continúa posteriormente durante la Guerra Civil Española, en la que tantos los republicanos como los sublevados promovieron un modelo tradicional de género por el que a la mujer se le asignaba el papel de ayudante y madre-esposa sufriente en la retaguardia, mientras que el hombre debía alistarse como soldado para defender y morir por la nación ${ }^{32}$. No hay que olvidar al respecto que, a pesar de su propagada presencia en la prensa y los carteles de guerra, las milicianas solo estuvieron en el frente unos pocos meses y los propios republicanos terminaron identificándolas con prostitutas ${ }^{33}$. Mary Nash resume la visión conservadora sobre el género sexual en el bando republicano con la siguiente frase, popular entre las mujeres de la época: «los hombres son comunistas, socialistas o anarquistas de cintura para arriba» ${ }^{34}$.

La concepción tradicional de la masculinidad prosigue después del triunfo de Franco, pero si durante la guerra se proponía una masculinidad militar, constituida por la fuerza física, la agresividad, la camaradería fraternal, el sacrificio y el estoicismo, tras el conflicto civil se retorna a la masculinidad respetable del pater familias de los años 30 por la necesidad de reconstruir España y forjar su futuro por medio de familias heteronormativas y para reproducir en cada una de ellas la jerarquía, los valores patriarcales y la ideología de la llamada Nueva España. Este modelo de hombre que ha sustituido la violencia necesaria en el combate por el orden, el trabajo y el matrimonio en la postguerra constituye la que se podría calificar como «masculinidad cívica», una masculinidad respetable que busca el bien y la estabilidad sociales.

30. LlonA, Miren: "Los otros cuerpos disciplinados: Relaciones de género y estrategias de autocontrol del cuerpo femenino (primer tercio del siglo XX)», Arenal, 14(1), 2007, p. 90.

31. Llona, Miren: «Las contradicciones de la respetabilidad. Género y cultura política socialista en el primer tercio del siglo XX", Historia, Trabajo y Sociedad, 5, 2014, p. 47.

32. GonZÁlEz-AlLENDE, Iker: Líneas de fuego: Género y nación en la narrativa española durante la Guerra Civil (1936-1939). Madrid: Biblioteca Nueva, 2011, p. 16.

33. NASH, Mary: Rojas: Las mujeres republicanas en la Guerra Civil. Madrid: Taurus, 1999, p. 169.

34. Ibid., p. 173. Frances Lannon ofrece la misma idea cuando indica que los militantes del POUM eran revolucionarios en cuestiones políticas, pero no en su concepción de la familia y las relaciones sexuales. Lannon, Frances: "Women and Images of Women in the Spanish Civil War", Transactions of the Royal Historical Society, 1, 1991, p. 220. 
En opinión de Mary Vincent, fue el carlismo el que proveyó en los primeros tiempos de la dictadura franquista este ideal de masculinidad basado en la familia y la paternidad, dejando atrás la masculinidad combativa de la Falange ${ }^{35}$. Como señala esta investigadora, se necesitaba una masculinidad que se centrara en el hogar en vez de en el cuartel para que se pudieran incorporar en ella los numerosos heridos y mutilados de guerra, así como los que padecían enajenación mental y neurosis como consecuencia del conflicto bélico ${ }^{36}$. De esta forma, la masculinidad subordinada de estos hombres que sufrían daños físicos y psicológicos se compensaba por medio de su función en la familia, donde ocupaban la posición dominante. La producción cultural franquista enfatizaba este cambio de masculinidad en obras como La vida nueva de Pedrito de Andía (1951), de Rafael Sánchez Mazas, que instaba a los jóvenes españoles a abandonar los valores propios de la masculinidad falangista, como la violencia y la fuerza física, por principios más acordes con la masculinidad cívica, como el control de los impulsos, la espiritualidad, la familia y el amor heterosexual ${ }^{37}$.

En contraposición con este modelo de masculinidad cívica, la dictadura franquista construye a sus enemigos, entre los que se hallan los exiliados republicanos, con una masculinidad deficiente e inadecuada para la nación. Los franquistas demonizan y se burlan de la masculinidad de los republicanos ya desde la Guerra Civil, ofreciendo una visión contradictoria de su virilidad: o bien se les describe con una masculinidad excesiva e incontrolable, como bestias que cometen actos salvajes e inhumanos, o bien se les representa con una masculinidad insuficiente, como afeminados y cobardes que huyen de las batallas ${ }^{38}$. Esta misma retórica fue utilizada por el bando republicano para referirse a los franquistas. La diferencia entre ambos bandos es que los republicanos tienden a mostrar al enemigo más como bestias, mientras que los franquistas enfatizan más la visión de los republicanos como cobardes.

La construcción de la masculinidad de los exiliados como inapropiada para la nación justifica para el régimen franquista su marcha de España. Del medio millón de personas que cruzó la frontera con Francia en 1939, la mayoría retornó al cabo de poco tiempo a España — de forma voluntaria o forzados por el gobierno francés-, mientras que alrededor de 150 mil individuos, los más comprometidos políticamente, permanecieron en el exilio, quedándose en Europa o partiendo a América ${ }^{39}$. En la composición de este

35. VinCENT, Mary: "La reafirmación de la masculinidad en la cruzada franquista", Cuadernos de Historia Contemporánea, 28, 2006, p. 150.

36. Ibid., pp. 145-8.

37. GonZÁlez-AlLENDE, Iker: «De héroe a santo: Masculinidad y españolidad en La vida nueva de Pedrito de Andia, de Sánchez Mazas", Revista Canadiense de Estudios Hispánicos, 36(3), 2012, p. 494.

38. GonZÁlez-Allende, Iker: "Masculinities in Conflict: Representations of the Other in Narrative during the Spanish Civil War", Hispanic Research Journal, 11(3), 2010, p. 195.

39. No existe un total acuerdo por parte de los investigadores en la cifra exacta de exiliados definitivos, variando entre 125.000 y 160.000 personas. Pla BRUGAT, Dolores: «Introducción», en Pan, trabajo y hogar: El 
exilio predominaban los hombres jóvenes, pero también había numerosas familias con mujeres, niños y ancianos ${ }^{40}$. Desde la doctrina franquista los exiliados son representados como hombres vencidos, es decir, débiles, además de peligrosos y anti-españoles, extranjerizados por las ideas de la Unión Soviética — «rojos» comunistas ${ }^{41}$. Por lo tanto, la dictadura considera positivo para la salud del cuerpo nacional su salida de España y va a prohibir el legado cultural de estos exiliados durante varias décadas.

En el conjunto de los dos millones de emigrantes españoles que en la década de 1960 partieron para el norte de Europa — mayormente Francia, Alemania, Suiza, Bélgica y Reino Unido - en busca de trabajo y de mejores condiciones de vida, también predominaron los varones. Félix Santos indica que la mayoría eran trabajadores poco cualificados, provenientes de la construcción, la industria, la pequeña empresa o la agricultura $^{42}$. Tras el Plan de Estabilización franquista de 1959, el cual forzó a numerosas empresas a cerrar y a despedir a sus trabajadores, los españoles se vieron forzados a emigrar a los países industrializados de Europa que necesitaban incorporar mano de obra extranjera en sus empresas.

La masculinidad de estos hombres emigrantes, jóvenes y enérgicos, suponía un problema para la dictadura franquista porque su pobreza, desempleo u ociosidad podían derivar en desórdenes, huelgas y protestas sociales. El franquismo promovió su emigración como una vía de escape de estas posibles tensiones internas ${ }^{43}$. Además, el régimen de Franco se benefició económicamente de las divisas que estos emigrantes mandaban a sus familiares en España, las cuales sirvieron para mejorar la maltrecha economía del país. De esta manera, tanto la salida de los exiliados como la de los emigrantes respondió a unos objetivos políticos por parte del franquismo. En ambos casos, los hombres resultaban amenazantes para el sistema, que los consideraba excesos, tumores del cuerpo nacional que impedían su buen funcionamiento. Su expulsión de España, por lo tanto, fue fomentada por la dictadura ${ }^{44}$.

exilio republicano español en América Latina. México D.F.: Segob-Instituto Nacional de Migración, 2007 , p. 20; ABellán, José Luis: El exilio como constante y como categoría. Madrid: Biblioteca Nueva, 2001, p. 70; FABER, Sebastiaan: Exile and Cultural Hegemony: Spanish Intellectuals in Mexico, 1939-1975. Nashville: Vanderbilt University Press, 2002, p. 15. Consuelo Soldevilla Oria señala que 30.000 de estas personas se exiliaron en América. Soldevilla Oria, Consuelo: El exilio español (1808-1975). Madrid: Arco Libros, 2001, p. 65.

40. Pla Brugat, Dolores: op. cit., p. 21.

41. Como expresa Xosé Manuel Núñez Seixas, durante la Guerra Civil cada bando negaba la condición de español a su oponente, presentando su lucha como una guerra de liberación contra el invasor. NúÑEz SeIXAs, Xosé Manuel: Suspiros de España: el nacionalismo español, 1808-2018. Barcelona: Crítica, 2018 , p. 65.

42. SANTos, Félix: Exiliados y emigrados: 1939-1999. Madrid: Fundación Españoles en el Mundo, 1999, p. 33.

43. VAlero-Matas, Jesús A. et al:: "El pasado vuelve a marcar el presente: La emigración española", Papeles de Población, 83, 2015, p. 50.

44. La emigración de españoles a partir de la crisis del 2008 también se debe a motivos políticos: las medidas de austeridad y los recortes presupuestarios del gobierno. A pesar de ello, los políticos minimizan 
Se podría suponer que los exiliados y emigrantes elaborarían un modelo alternativo de masculinidad española hegemónica, pero su visión de la masculinidad resulta muy similar a la masculinidad cívica franquista, exceptuando lo referente a la religión católica. De esta manera, los españoles desplazados se rigen también por una división clara y tradicional entre los papeles de los hombres y de las mujeres, por la cual los varones construyen su identidad masculina por medio del trabajo, la paternidad, la conducta moral y el cuidado y la protección de su familia. Así se aprecia en las cartas de súplica que los exiliados españoles enviaban al Comité Técnico de Ayuda a los Republicanos Españoles (CTARE) en México o al Servicio de Evacuación de Republicanos Españoles (SERE). Guadalupe Adámez Castro ha analizado cómo en estas cartas, escritas mayoritariamente por hombres, predominan solicitudes relacionadas con el mundo laboral o la reunificación familiar ${ }^{45}$. Como ejemplo, en una de ellas, firmada por Juan Zabala desde un campo de concentración francés donde se halla retenido, se constata la primacía de la masculinidad cívica:

[...] siendo tan grandes mis deseos el salir de esta mísera vida del campo y poder reunirse uno con la familia, que también se encuentra refugiada, y poder reconstruir el hogar deshecho, trabajar y ser libre en uno de los países generosos que nos acogen [... $]^{46}$.

El mismo modelo de masculinidad encuentra Elena Díaz Silva en la comunidad de exiliados españoles en México, en la que el Boletín al Servicio de la Emigración Española, publicado por el CTARE, subrayaba el carácter trabajador y emprendedor de los españoles para contrarrestar la visión negativa que existía de ellos en la sociedad mexicana ${ }^{47}$. Además, a la hora de evaluar las solicitudes de préstamos de los exiliados, el CTARE primaba valores típicos de la masculinidad cívica como el ser serio, responsable, trabajador, llevar una vida saludable, estar casado y vivir en compañía de la esposa e hijos ${ }^{48}$.

La familia también constituye un componente primordial en los emigrantes españoles durante el franquismo. De hecho, la necesidad de proveerla es la razón principal por la que los hombres emigraron. Así lo señala el protagonista de Vida de un emigrante español: El testimonio auténtico de un obrero que emigró a Alemania (1979), escrita por el emigrante Víctor Canicio a partir de una historia real: «mientras me dejen, me

esta realidad y sus efectos negativos en la salud mental de los emigrantes al calificarla, como hizo en el 2012 Marina del Corral, Secretaria de Inmigración, como resultado del «impulso aventurero de la juventud».

45. AdÁmez CAStro, Guadalupe: «Un pasaporte hacia la libertad: Súplicas y solicitudes de los exiliados españoles al Comité Técnico de Ayuda a los Republicanos Españoles (CTARE)", Vinculos de Historia, 5, 2016, p. 304.

46. Adámez Castro, Guadalupe: Gritos de papel: las cartas de súplica del exilio español (1936-1945). Granada: Comares, 2017, p. 108.

47. Díaz Silva, Elena: Héroes, indeseables y vencidos: La quiebra y la reconstrucción del modelo de masculinidad republicano en el exilio mexicano. Granada: Comares, 2019, p. 166.

48. Ibid., pp. 178-9. 
quedo en Alemania. [...] Tengo una familia que ha de llenar la barriga todos los días»49. La paternidad se erige como un rasgo fundamental de la masculinidad de los hombres de la clase trabajadora. David Collinson y Jeff Hearn indican que estos hombres redefinen su sentido de dignidad frente a la sociedad que les devalúa enfatizando valores masculinos que les hagan sentirse más valiosos, como el de proveer a su familia ${ }^{50}$. De esta forma, su papel de proveedores y el respeto social que obtienen por ello les sirve para contrarrestar su falta de poder en la sociedad capitalista, su masculinidad marginalizada.

Las condiciones de vida en el país de acogida también posibilitaron a los emigrantes españoles la adopción de nuevas costumbres que resultan típicas de la respetabilidad y de la masculinidad cívica, como el disfrute del hogar. Así lo manifiesta el protagonista de Canicio:

Yo en la Emigración he ido cambiando mucho. Llegué acostumbrado a la vida de España, a la tertulia con los amigos y a la mujer siempre en casa. Aquí, en cambio, debido a que la sociedad alemana no te admite, a que vienes a ahorrar un dinero y no a malgastarlo [...], no me podía permitir yo el lujo de alternar. Me hice un hombre de casa. [...] Los inviernos son largos y empecé a leer libros [... $]^{51}$.

Resulta interesante esta metamorfosis que experimenta el emigrante al sustituir el espacio público, generalmente asignado al hombre, por el espacio privado, reemplazando la masculinidad de la calle, propia de España, por la masculinidad del hogar en Alemania.

La concepción tradicional de género de los hombres españoles desplazados se puede explicar no solo por la educación recibida en España — lo que justificaría su semejanza a la masculinidad franquista—, sino también por el hecho de que estaban reconstruyendo sus vidas alejados de su nación, por lo que el mantenimiento de una masculinidad claramente opuesta a la feminidad les confería seguridad y estabilidad identitaria frente a los cambios e incertidumbres que experimentaban en el nuevo país.

49. CANICIO, Víctor: Vida de un emigrante español: El testimonio auténtico de un obrero que emigró a Alemania. Barcelona: Gedisa, 1979, p. 188. La emigración la ve como una oportunidad de mejorar el futuro de su hijo con poliomielitis: "Yo tenía que sacar al niño mío de esa situación porque allí, en León, todo el que estaba cojo era o limpiabotas o zapatero. Mi hijo tenía que ser algo más. Bastante más que yo, además. Me decidí a emigrar» (p. 61).

50. Collinson, David L. y Hearn, Jeff: «Men at Work: Multiple Masculinities/Multiple Workplaces». En: MaC an GHaill, Máirtín (ed.): Understanding Masculinities: Social Relations and Cultural Arenas. Buckingham: Open University Press, 1996, p. 68.

51. Canicio, Víctor: op. cit., pp. 120-1. 
3. Del REForzamiento de la masculinidad a la EMASCUlaCión de lOS hombres DESPLAZADOS

Aunque el exilio y la emigración suelen causar retos y fisuras en la masculinidad de los hombres, asimismo generan situaciones que pueden reforzar su valía masculina. Entre las consecuencias positivas del abandono de la nación, se hallan la ampliación de perspectivas y el crecimiento personal, pudiendo incluso experimentarse un rito de paso a la masculinidad, como queda reflejado en la novela autobiográfica El otro árbol de Guernica (1967), en la que Luis de Castresana relata cómo vivió su infancia exiliado en Bélgica tras ser evacuado por el Gobierno Vasco durante la Guerra Civil. Los exiliados también pueden sentirse seguros y renacidos en el país de acogida tras las penurias vividas durante el conflicto bélico. Por ejemplo, el poeta Juan Gil-Albert recobró en México la alegría de vivir y el disfrute del ocio: «Fueron unos meses en los que ni siquiera había proyecto; cada cual vivía de sus fuerzas vírgenes aspirando las primicias del aire, recreándose en su inconsciencia, en tregua del deber» ${ }^{52}$.

Este sentimiento de fácil adaptación al exilio lo expresó el filósofo José Gaos por medio del término "transterrado» para enfatizar la continuidad de costumbres y de idioma que los exiliados republicanos encontraron en México. Sin embargo, numerosos exiliados rechazaron el término porque implicaba la desestimación del dolor provocado por el desarraigo ${ }^{53}$. Lo que sí es cierto es que algunos intelectuales exiliados tuvieron facilidades en México para retomar sus labores culturales en instituciones como la Casa de España, donde llegaron a ganar más dinero que sus homólogos mexicanos ${ }^{54}$. En referencia a los escritores exiliados, José María Naharro-Calderón señala que disfrutaron de «unas condiciones de sobrevivencia muy superiores a las de sus colegas del interior ${ }^{55}$.

52. Gil-Albert, Juan: Tobeyo o del amor: Homenaje a México. Valencia: Pre-Textos, Instituto de Cultura Juan Gil-Albert, 1990, p. 65.

53. VAlero Pie, Aurelia: "Metáforas del exilio: José Gaos y su experiencia del 'transtierro', Revista de Hispanismo Filosófico, 18, 2013, p. 75. El filósofo exiliado Eduardo Nicol expresaba así su desacuerdo con el concepto de transtierro, culpando a Gaos de querer complacer con él a la sociedad mexicana: "Cierto es que la planta se transplanta y fructifica en tierras diferentes de aquella donde brotó por primera vez. Pero la tierra del hombre, como su lengua, no es cosa que pueda permutarse. [...] Y quien declara que ha renunciado íntimamente, para siempre, a su tierra, y adopta la otra, solo hace méritos para obtener popularidad». LLERA, Luis de: «El falso concepto de transtierro». En: Ascunce, José Ángel (ed.): El exilio: Debate para la historia y la cultura. Donostia: Saturrarán, 2008, p. 72.

54. FABER, Sebastiaan: op. cit., p. 22.

55. NAHARRo-CALderón, José María: Entre el exilio y el interior: El 'entresiglo' y Juan Ramón Jiménez. Barcelona: Anthropos, 1994, p. 100. En La vuelta: 1964, Max Aub reconoce por medio del personaje de Mariana que los que vivieron bajo la dictadura fueron los verdaderos exiliados por el sufrimiento que padecieron: "Tú regresas ahora. No sabrás nunca lo que fue esto, de 1940 a 1950. Las cárceles llenas. El miedo. El hambre. No poderse mover. No escribir. No poder publicar. Pasé años enteros sin ver a nadie, sin saber de nadie». Aub, Max: Las vueltas. México D.F.: Joaquín Mortiz, 1965, p. 64. 
Ahora bien, en opinión de Alicia Alted, la mayoría de los exiliados en México tuvieron al comienzo dificultades de adaptación y se vieron obligados a trabajar en distintos oficios antes de conseguir estabilidad económica, aunque con el tiempo, una gran parte de ellos prosperó económicamente y llegó a formar parte de la clase media-alta ${ }^{56}$.

La mejora económica también supuso la principal consecuencia positiva en la masculinidad de los hombres emigrantes en los años 60. Al ganar más dinero y poder mantenerse a sí mismos y a sus familias, aumentó su satisfacción personal y su autoestima masculina. El trabajo que un hombre realiza y el sustento y estatus económico que obtiene de él influyen significativamente en su concepción de la masculinidad. Como indica Victor Seidler, el trabajo es la fuente misma de la identidad masculina ${ }^{57}$. Consecuentemente, el desempleo o los trabajos precarios y el no poder realizar la función de proveedor les hace a los hombres sentirse emasculados y pueden perder el respeto e incluso la obediencia de su familia ${ }^{58}$. En este sentido, el incremento de la capacidad adquisitiva de los emigrantes españoles favoreció su valía como hombres. Como apunta Antonio Muñoz Sánchez, su objetivo era reunir dinero para regresar después a España y mejorar sus condiciones de vida, mayormente comprando un piso o un local59. Así expresa el protagonista de Vida de un emigrante español su ascenso social en Alemania: «No tengo el piso puesto como un capitalista pero me encuentro a gusto. Estoy en mi casa, me cojo un libro, me siento en mi sillón y lo leo cómodamente. O me veo mi televisor, que lo tengo en color también " ${ }^{60}$.

Además de ganar más dinero, los emigrantes españoles se sentían mejor valorados en sus puestos de trabajo, lo que repercutía positivamente en su autoestima masculina. En Con la maleta al hombro (1965), un libro de impresiones del periodista y escritor Ángel María de Lera sobre sus visitas a los emigrantes españoles en Alemania, un joven extremeño lo manifiesta de esta manera: «aquí trabaja todo el mundo. Eso por un lado. Por otro, que estos alemanes saben apreciar el trabajo y lo pagan bien. Yo, en cuanto me descuido, ahorro mil duros" ${ }^{61}$. Sin embargo, esta opinión positiva contrasta con las de otros emigrantes que enfatizaban situaciones de abuso en el trabajo.

56. Alted Vigil, Alicia: La voz de los vencidos: El exilio republicano de 1939. Madrid: Aguilar, 2005, pp. 229 y 242.

57. SEIDLER, Victor J.: Rediscovering Masculinity: Reason, Language and Sexuality. London: Routledge, 1989, p. 151.

58. Donaldson, Mike y Howson, Richard: «Men, Migration and Hegemonic Masculinity». En: Donaldson, Mike et al. (eds.): Migrant Men: Critical Studies of Masculinities and the Migration Experience. New York: Routledge, 2009, p. 212.

59. MuÑoz SÁNCHEZ, Antonio: «Una introducción a la historia de la emigración española en la República Federal de Alemania (1960-1980)", Iberoamericana, 12(46), 2012, p. 32.

60. Canicio, Víctor: op. cit., p. 145.

61. LerA, Ángel María de: Con la maleta al hombro: Notas de una excursión por Alemania. Madrid: Editora Nacional, 1966, p. 63. 
Finalmente, el exilio y la emigración posibilitan una mayor libertad lejos del control social y familiar. Al encontrarse solo en Alemania, el protagonista de Hemos perdido el sol (1963) — novela que Ángel María de Lera publicó sobre los españoles emigrantes en Alemania- puede disfrutar más de la vida: "Yo no he empezado a vivir hasta ahora. Nunca había bebido champaña, ni comido en restaurantes, ni bailado en cabarets, ni paseado en coche ${ }^{62}$. Esta circunstancia afectaba especialmente a los hombres homosexuales, quienes, al hallarse en un país donde eran anónimos y desconocidos, podían explorar su sexualidad y establecer relaciones sentimentales con mayor libertad. Tal fue el caso de Juan Gil-Albert y Luis Cernuda, que hallaron en su exilio mexicano relaciones amorosas de gran significación en sus vidas. Cernuda decidió abandonar su trabajo como profesor en una universidad estadounidense y trasladarse a México por este motivo: "Creo que ninguna otra vez estuve, si no tan enamorado, tan bien enamorado. [...] jamás en mi juventud me sentí tan joven como en aquellos días en México» ${ }^{63}$. Terenci Moix también revela en sus memorias cómo su emigración en Londres le permitió explorar múltiples formas de erotismo y sexualidad y hallar el amor en un joven americano: «Viniendo de la España de Franco, ese rincón se parecía mucho a la libertad soñada” ${ }^{64}$.

Ahora bien, como han señalado diversos estudiosos de las migraciones gays, en el nuevo país los hombres desplazados pueden sufrir abusos por su situación de indefensión o estar controlados por sus compatriotas, quienes a menudo constituyen su soporte básico, lo que provoca que no dispongan de tanta libertad para expresar su identidad sexual65. Así, la emigración de las personas gays no consiste sólo en un movimiento que conduce de la represión a la liberación. Eithne Luibhéid indica que esta visión supone una simplificación del movimiento migratorio y un olvido de las luchas y sufrimientos que las personas gays padecen en el país de acogida ${ }^{66}$.

A pesar de estas oportunidades que favorecen la satisfacción vital de los hombres desplazados, el exilio y la emigración generan numerosas situaciones que desestabilizan su virilidad. La valía masculina de los hombres exiliados se vio afectada por la derrota bélica que padecieron, así como por el trato que recibieron al cruzar la frontera con Francia, donde fueron desarmados por las autoridades de ese país y en numerosas ocasiones confinados en campos de concentración, donde sufrieron pésimas condiciones de vida. En el recuerdo de su paso por uno de esos campos de concentración, Juan

62. Lera, Ángel María de: Hemos perdido el sol. Madrid: Aguilar, 1970, p. 318.

63. Cernuda, Luis. "Historial de un libro", Obra completa. Vol. 2. Madrid: Siruela, 1993, p. 656.

64. MoIx, Terenci: Extraño en el paraíso. Barcelona: Planeta, 1998, p. 322.

65. VÁsQUEZ del ÁGuILA, Ernesto: Being a Man in a Transnational World: The Masculinity and Sexuality of Migration. New York: Routledge, 2014, p. 143.

66. LuIBHÉID, Eithne: "Introduction: Queering Migration and Citizenship», en Queer Migrations: Sexuality, U.S. Citizenship, and Border Crossings. Minneapolis: University of Minnesota Press, 2005, p. XXV. 
Martínez enfatiza la deshumanización que sufrieron: «Miserable cuadro el de ese pueblo vencido. Millares de ellos con barbas de quince días, estropajosos en sus vestimentas a causa de mes y medio de retirada [...] y ahí tirados en la arena, aumentaba el aspecto trágico de nuestra lucha y de nuestra derrota ${ }^{67}$. Hubo hombres que enloquecieron o enfermaron y unos doscientos llegaron a morir ${ }^{68}$. El maltrato a los españoles se debió no solo a que el gobierno francés se sintió desbordado por la cantidad de personas que cruzaron la frontera, sino también a su consideración como hombres peligrosos e «indeseables» por la propaganda que les presentaba como "rojos» extremistas.

Si los exiliados se sentían como derrotados, algunos emigrantes también creían que se les había expulsado de España y se les había menospreciado. Así lo expresa el protagonista de Hemos perdido el sol: "Estamos en Alemania, ¿no? ¿Y por qué? Porque en España no tenemos sitio. Nos echaron de allí, como quien dice» ${ }^{69}$. Los que salían de España en expediciones oficiales llegaban en grupo al nuevo país, donde les realizaban exámenes médicos para asegurarse de que eran aptos para trabajar y no contagiarían a su nación. Como recogen diversos testimonios, su trato fue asimismo deshumanizante y se sentían como parte de un ganado. Las barracas o residencias donde les alojaron fueron construidas al lado de las empresas para las que trabajaban para fomentar así su productividad. Allí los hombres compartían literas y sentían que habían vuelto a la época de la mili. Este control de los hombres desplazados por parte de los gobiernos de acogida muestra cómo su masculinidad se estereotipa como inadecuada para la nación en dos extremos opuestos: o peligrosos o infantiles.

Los matrimonios de emigrantes no podían vivir juntos en la misma residencia por no ser éstas mixtas, por lo que se veían en contadas ocasiones. Los hombres que habían dejado a su familia en España padecían aún más la soledad, llegando a utilizar los servicios de prostitutas o manteniendo relaciones amorosas extramatrimoniales. Lera justifica el adulterio de estos emigrantes por la ausencia de sus esposas, mostrando la perspectiva falócrata de la época: «nuestro emigrante es un hombre incompleto. Y,

67. Alted Vigil, Alicia: op. cit., p. 71.

68. Ibid., p. 77.

69. Lera, Ángel María de: op. cit., p. 85. Para Lera, el hecho de que los emigrantes se vean obligados a abandonar España para poder subsistir les convierte en realidad en exiliados (Con la maleta..., p. 14). Lera fue muy crítico con el régimen franquista por permitir que los hombres criados y formados en España "a costa del trabajo, de los bienes y servicios de la nación» beneficien económicamente ahora a otros países (Ibid., p. 207). Estos mismos argumentos los esgrime desde el 2013 Marea Granate, el colectivo de emigrantes españoles críticos con el gobierno español, en su activismo por internet bajo el lema de «No nos vamos, nos echan». Cogo, Denise y Nihil Olivera, Mauricio: «NoNosVamosNosEchan - Internet, activismo en red y narrativas de los nuevos emigrantes españoles", Matrizes, 11(1), 2017, p. 7. Uno de esos emigrantes en Francia, Gonzalo Gómez Montoro, manifiesta en España no nos quiere: Una visión diferente de la emigración española actual (2017), la sensación de fracaso por tener que irse fuera de España a trabajar. http:// aguasdeceniza.blogspot.com/2017/10/espana-no-nos-quiere-una-seleccion-de.html. 
además, un hombre torturado porque su edad y los hábitos eróticos adquiridos en el matrimonio [...] han contribuido a la irrenunciabilidad del ejercicio sexual» ${ }^{70}$. En el caso de los exiliados, durante los primeros años fueron comunes las separaciones familiares, lo que afectaba a su papel de padres de familia. El embajador Ángel Ossorio mostraba su angustia por esta razón en una carta fechada en 1938 en Buenos Aires: «Mi mujer, mi hija y yo estamos sufriendo el desgarrón familiar. Vernos, a estas alturas de la vida, separados de todos los hijos, nueras, nietos y hermanos, es gran dolor ${ }^{71}$.

La falta de dinero y las dificultades laborales, teniendo que trabajar en posiciones de menos prestigio que en España, asimismo supusieron un reto para la masculinidad de los exiliados, especialmente al comienzo de su destierro. En los países de acogida numerosos intelectuales españoles tuvieron que empezar a trabajar de traductores, profesores o editores para poder ganarse la vida. Por ejemplo, Cernuda tuvo que recurrir a sus amigos para poder sobrevivir durante su exilio en Europa: «Fue aquella una de las épocas más miserables de mi vida: sin recursos, como dije, sin trabajo, solo la compañía y la ayuda de otros amigos y conocidos cuya situación era semejante a la mía me permitieron esperar y salir adelante ${ }^{72}$.

Por otro lado, el exilio y la emigración tendieron a modificar las dinámicas de género en las familias, ya que ofrecían nuevas oportunidades laborales a las mujeres. Los hombres aceptaban que sus mujeres trabajaran fuera de casa de forma temporal por las necesidades económicas de la familia ${ }^{73}$, sin que realmente apoyaran un cambio en su concepción tradicional de género. Tal fue el caso de la intelectual Pilar de Zubiaurre, que trabajó en México con el doctor Gonzalo Rodríguez Lafora desde 1942 hasta 1948, momento en que su marido, el crítico de arte Juan de la Encina, se estableció profesionalmente al comenzar a enseñar en la $\mathrm{UNAM}^{74}$.

La misma actitud mantenían los hombres desplazados en los años 60, quienes generalmente emigraban solos para ahorrar dinero y después traer a su familia al nuevo país. En las ocasiones en las que el marido y la mujer emigraban juntos, solían dejar a sus hijos en España a cargo de los abuelos y la mujer también trabajaba en una fábrica para mejorar la economía familiar. Sin embargo, esta situación no solía ser del agrado del esposo, que lo toleraba por el contexto en que se hallaban. Así lo manifiesta el protagonista de Hemos perdido el sol: «Mi mujer, por ejemplo, trabaja ahora por una circunstancia muy especial. Pero si viviéramos normalmente, yo preferiría que

70. Lera, Ángel María de: Con la maleta..., p. 87.

71. González-Allende, Iker (ed.): Epistolario de Pilar de Zubiaurre (1906-1970). Woodbridge: Tamesis, 2014, p. 143 .

72. Cernuda, Luis: op. cit., p. 644.

73. Fernández Asperilla, Ana: «Estrategias migratorias: Notas a partir del proceso de la emigración española en Europa (1959-2000)», Migraciones E Exilios, 1, 2000, p. 75.

74. GonZÁlez-Allende, Iker: "Pilar de Zubiaurre: de la modernidad a la evocación». En: Zubiaurre, Pilar de: Evocaciones: Artículos y diario (1909-1958). San Sebastián: Saturrarán, 2009, p. 42. 
ella estuviese en casa, para cuidar del niño y de mí»75. De esta manera, un cambio de comportamiento en el matrimonio de emigrantes españoles raramente implicaba un cambio real de la forma en la que el hombre entendía y valoraba el género.

La masculinidad de los emigrantes también se veía afectada por la explotación laboral — teniendo que trabajar bajo cronómetro y de manera automática-, las diferencias de sueldos respecto a los alemanes y los accidentes de trabajo que padecían. Los españoles en Alemania sólo vivían para trabajar, para ahorrar dinero y poder ayudar a su familia y retornar antes a España. En Vida de un emigrante español, Canicio denuncia los daños físicos que sufrían los obreros españoles por las malas condiciones laborales: "A muchísima gente, con accidentes graves encima, los han largado después a España, pero con cajas destempladas ${ }^{76}$.

Además de la deshumanización de los emigrantes en el ámbito laboral, múltiples realidades del país de acogida que resultaban diferentes a España provocaban su sensación de alienación y emasculación, entre ellas la comida, el clima y el desconocimiento del idioma. Esto causaba que raramente se relacionaran con los alemanes y que vivieran separados de ellos. Al no entender ni hablar el alemán, aumentaba en ellos su sensación de marginación. Así lo revela el protagonista de Hemos perdido el sol: "No se han dado cuenta de que existo yo y de que estoy aquí. No les importo lo más mínimo. Y aunque les importara, ¿qué podrían decirme? ¿Qué podría decirles yo? Si me uniera al grupo, ¿cómo nos entenderíamos? Imposible. Este endiablado idioma nos separa ${ }^{77}$. Los españoles también debían enfrentarse a una concepción distinta del género, ya que en Alemania las mujeres actuaban con una mayor libertad e independencia. Esto provocaba que la mayoría de los hombres españoles prefiriera a las mujeres españolas para sus planes de matrimonio, ya que éstas mantenían una visión tradicional del género que no desestabilizaba su masculinidad ${ }^{78}$.

Los hombres exiliados españoles asimismo tuvieron dificultades para adaptarse a su nueva vida. En México se sintieron impresionados por la pobreza y la suciedad y tuvieron que acomodarse a costumbres, alimentos y lengua distintos, además de a la altura del país ${ }^{79}$. La distancia geográfica de España y la imposibilidad política y moral de regresar a su país influyeron en su sensación de desarraigo y en la crisis de su masculinidad. Un ejemplo significativo fue el de Juan José Domenchina, secretario de Manuel Azaña, quien en poemas como «El ex-hombre» reflejaba su masculinidad herida. Además de él, otros exiliados como Juan Ramón Jiménez manifestaron una

75. Lera, Ángel María de: Hemos perdido..., p. 341.

76. CANicio, Víctor: op. cit., p. 164.

77. Lera, Ángel María de: op. cit., pp. 148-9.

78. GonzÁlez-Allende, Iker: «Displaced Spanish Men: Masculinity, Sexuality and Migration in Hemos perdido el sol (1963), by Ángel María de Lera”, Romance Quarterly, 66(4), 2019, p. 213.

79. Alted Vigil, Alicia: op. cit., pp. 221-2. 
profunda nostalgia alejados de España. En sus memorias, Concha Méndez, exiliada en México, relata la historia de un compatriota cuya inadaptación le llevó a morir solo hasta que descubrieron su cadáver por el olor que procedía de su piso ${ }^{80}$. La esposa de Domenchina, la poeta Ernestina de Champourcin, señalaba al respecto que las mujeres sobrellevaron con mayor entereza que los hombres la vida en el exilio ${ }^{81}$.

La masculinidad de los hombres desplazados también se ve afectada negativamente por los numerosos casos de discriminación, rechazo y xenofobia que padecieron en los países de acogida. A pesar de la generosidad del presidente Lázaro Cárdenas, en México los exiliados españoles no fueron bien recibidos por los sectores conservadores, mientras que los grupos de izquierda también desconfiaban de ellos por su conexión histórica con los conquistadores. Alted Vigil indica que se les llamaba despectivamente «refugachos» y que a más de uno le dijeron que se volviera a su tierra ${ }^{82}$. Además, no se les permitió participar en la política mexicana, lo que, según Sebastiaan Faber, generó en ellos una sensación de "parálisis forzada" ${ }^{33}$. Faber señala que muchos exiliados españoles no expresaron públicamente hasta los años 80 las discriminaciones y los conflictos que padecieron en México por su agradecimiento al gobierno de Cárdenas ${ }^{84}$. Un caso significativo fue el del filósofo Eduardo Nicol, quien manifestó así su falta de aceptación por parte de la sociedad mexicana: "Aunque pasara dos siglos de mi vida aquí, yo seguiría siendo un español para los mexicanos. [...] yo en México he llevado la mitad de la vida que hubiera llevado en España" ${ }^{85}$.

Similares impresiones reflejan los testimonios de los emigrantes españoles en Alemania, que soportaban insultos e incluso ataques físicos y tenían prohibido entrar en ciertos locales. En el documental El tren de la memoria (2005), dirigido por Marta Arribas y Ana Pérez, uno de los emigrantes comenta cómo los hombres españoles tenían que ir en grupo en las calles y los bares porque había alemanes que siempre buscaban pelearse con ellos. El protagonista de Vida de un emigrante español también resalta el maltrato sufrido en Alemania: «Durante muchos años he sido el clásico ciudadano de segunda clase. No he tenido derecho a voz ni a voto. He sido discriminado y marginado por una sociedad que no me admitía, que no me daba posibilidades de integración„ 86 .

80. MÉNDEZ, Concha: Memorias habladas, memorias armadas. Ed. Paloma Ulacia Altolaguirre. Madrid: Mondadori, 1990, p. 120.

81. Champourcin, Ernestina de: La ardilla y la rosa: Juan Ramón en mi memoria. Huelva: Ediciones de la Fundación Juan Ramón Jiménez, 1996, p. 133.

82. Alted Vigil, Alicia: op. cit., p. 230.

83. FABER, Sebastiaan: «Silencios y tabúes del exilio español en México: Historia oficial vs. historia oral", Espacio, tiempo y forma, Serie V, Historia Contemporánea, 17, 2005, p. 375.

84. Ibid., p. 377.

85. Llera, Luis de: op. cit., p. 73.

86. Canicio, Víctor: op. cit., p. 186. 
Como consecuencia de la discriminación que padecieron y de su sensación de fracaso y alienación, los hombres desplazados adoptaron comportamientos tradicionalmente considerados poco viriles como el lamento, el llanto, el miedo y la locura. Estas actitudes entran en oposición con uno de los rasgos principales de la masculinidad hegemónica, el ser capaz de resistir las situaciones estresantes, tanto físicas como emocionales ${ }^{87}$. Elena Díaz Silva recoge testimonios de exiliados en México que corroboran el padecimiento de problemas mentales entre los españoles, tales como neurastenias y depresiones, que provocaron un número elevado de suicidios ${ }^{88}$.

Entre los hombres emigrantes españoles también fueron frecuentes los casos de pérdida de la estabilidad emocional y mental. Lera describía su situación como una infantilización de su carácter: "A veces son infantiles. Cualquier pequeño contratiempo [...] que les hubiera sorprendido igualmente en España adquiere para ellos dimensiones de tragedia ${ }^{89}$. Precisamente esta es una de las consecuencias de lo que Joseba Achotegui denomina estrés o duelo migratorio: la regresión de los emigrantes, adoptando actitudes infantiles y conductas de dependencia y de protesta ${ }^{90}$. Como ejemplo, en Vida de un emigrante español, Canicio describe cómo un español enloquece de nostalgia en Alemania:

tuvimos que obligarle casi a regresar a España porque si no, se vuelve majareta. [...] Al final sentía unos dolores por todo el cuerpo que no podía ni trabajar casi. Pasar la frontera y desaparecerle fue todo uno, así que se conoce que, en el fondo, se trataba de un trastorno psíquico ${ }^{91}$.

\section{ESTRATEgIAS DE REMASCULINIZACIÓN}

Para hacer frente a estas múltiples realidades que suponen un reto a su masculinidad cívica tradicional, los hombres desplazados recurren a diversas estrategias para remasculinizar su identidad. Así, para contrarrestar su imagen de vencidos, enfatizan su compromiso político y la consideración de sí mismos como los auténticos representantes de España, es decir, su dignidad moral. Sánchez Vázquez lo manifiesta claramente: "No se trataba de una comunidad de vencidos o derrotados, aunque atravesaban el océano derrotados material, militarmente. [...] se sentían fuertes moralmente y, sobre todo, superiores a sus vencedores en el campo de batalla»92. León Felipe expresó la

87. Beneke, Timothy: Proving Manhood: Reflections on Men and Sexism. Berkeley: University of California Press, 1997, p. 36.

88. Díaz Silva, Elena: op. cit., pp. 168-9.

89. Lera, Ángel María de: Con la maleta..., p. 187.

90. Aснотеgui, Joseba: "Emigrar hoy en situaciones extremas: El síndrome de Ulises», Aloma, 30(2), 2012, p. 82.

91. Canicio, Víctor: op. cit., p. 98.

92. SÁnCHEZ VÁzQuez, Adolfo: op. cit., p. 23. 
misma idea en Español del éxodo y del llanto (1939); los exiliados se llevaban con ellos la auténtica voz de España: "Tú te quedas con todo / y me dejas desnudo y errante por el mundo... / mas yo te dejo mudo... ¡Mudo! / ¿Y cómo vas a recoger el trigo / y a alimentar el fuego / si yo me llevo la canción?»93. Los exiliados también veían su destierro como una prueba del destino a la que se debían enfrentar con estoicismo, equiparando su sufrimiento al de un mártir o un ser superior. Al enfatizar su resistencia y sacrificio se arrogaban características normativas de la masculinidad.

La participación en la política y el asociacionismo asimismo reafirmaron su identidad y seguridad masculina. Jorge de Hoyos ha analizado los múltiples proyectos políticos - a menudo contrapuestos - de los exiliados republicanos en los años 40 y cómo mantuvieron la esperanza de la caída del régimen franquista hasta el fracaso del gobierno de José Giral en 1947 por la falta de apoyo internacional ${ }^{94}$. Los emigrantes españoles también se politizaron en Alemania, aunque muchos de ellos sentían apatía, cuando no rechazo, ante la actividad política y sindical, entre otros motivos por temor a sufrir represalias al regresar a España ${ }^{95}$. Sin embargo, como estudia Marta Latorre Catalán, frente al apoliticismo en el que habían vivido bajo la dictadura franquista, Alemania les posibilitó el aprendizaje de la democracia y la participación en manifestaciones antifranquistas y reivindicaciones sociolaborales ${ }^{96}$. Este activismo confirió un mayor sentido a su existencia y les hizo sentirse más valorados.

En otras ocasiones, los hombres desplazados recurrieron a la agresividad y la violencia para compensar la opresión e impotencia que sentían en la sociedad de acogida y demostrar que seguían siendo viriles. Por ejemplo, hubo españoles que se enfrentaron a sus jefes en las fábricas o reaccionaron de manera violenta cuando les insultaban o sentían que se burlaban de ellos. Este tipo de comportamiento se ha descrito como «masculinidad de protesta». A pesar de la utilidad de este término, es importante evitar la estigmatización de los hombres desplazados o de clase trabajadora y notar que no son los únicos varones que actúan de una forma agresiva.

Los hombres desplazados también adoptaron actitudes masculinas tradicionales para sentir continuidad con las vidas que tenían antes de abandonar España, tales como el rechazo a la debilidad, la homofobia, la misoginia y la conquista de mujeres. En este sentido a veces mostraron admiración por modelos clásicos de la masculinidad española, como el don Juan y el torero, para reforzar no sólo su virilidad, sino también

93. Felipe, León: Español del éxodo y del llanto. http://www.cervantesvirtual.com/obra-visor/espanoldel-exodo-y-del-llanto-doctrina-elegias-y-canciones/html/.

94. Hoyos Puente, Jorge de. "Los difíciles años 40 para el exilio republicano de 1939", Historia y Memoria de la Educación, 9, 2019, p. 52.

95. SANZ DíAz, Carlos: «Emigración económica, movilización política y relaciones internacionales. Los trabajadores españoles en Alemania, 1960-1966", Cuadernos de Historia Contemporánea, 23, 2001, p. 322.

96. Latorre Catalán, Marta: "Ciudadanos en democracia ajena: Aprendizajes políticos de la emigración de retorno española en Alemania durante el franquismon, Migraciones E Exilios, 7, 2006, p. 90. 
su identidad nacional. En esos casos era común que existiera por parte de los exiliados republicanos una idealización y nostalgia de España y la reproducción de una retórica imperialista ${ }^{97}$, y por parte de los emigrantes un folclore basado en valores como el sol y la alegría españoles. En ambas situaciones se terminaba ofreciendo una visión del país no muy alejada de la que propagaba el franquismo.

\section{CONCLUSIONES}

El desplazamiento territorial forzado implica un desafío tanto a la identidad nacional del hombre como a su masculinidad tradicional. Los exiliados republicanos y emigrantes españoles de los años 60 se vieron obligados a abandonar España y comenzar una nueva vida en países con diferentes costumbres y a menudo con distintos modelos de género. Debido a sus ideas políticas o a su clase social, la dictadura franquista promovió su salida fuera de España, etiquetando su masculinidad como peligrosa, sobrante e inadecuada para el progreso y el futuro de la nación. Los países de acogida asimismo desconfiaron de ellos y estigmatizaron su masculinidad como políticamente extremista en el caso de los exiliados y brusca o infantil en el caso de los emigrantes.

El rechazo y la discriminación que los varones desplazados padecieron en la nueva sociedad, junto a su sensación de fracaso y de alienación, influyeron negativamente en su autoestima masculina, creando fisuras en el modelo de masculinidad cívica que traían de España, basado en la paternidad, el trabajo, la respetabilidad y la participación pública para el bien social. Estos hombres reaccionaron de múltiples formas a sus desafíos vitales en los países de acogida, pudiendo buscar desde una continuidad hasta una ruptura tanto en su identidad nacional española como en su modelo de masculinidad. Aunque algunos españoles desplazados se adaptaron fácilmente al nuevo país y/o adquirieron una masculinidad más flexible, la mayoría de ellos idealizaba o sentía nostalgia por lo que había perdido, por la España lejana y su virilidad allí, aferrándose a los valores nacionales y masculinidad española tradicional para sentirse más válidos y compensar sus padecimientos y emasculación en el extranjero.

97. FABER, Sebastiaan: Exile and Cultural Hegemony..., p. 48. 